desirability of making arrangements for the future preservation of the collection, Dr. Davis entered into negotiations about a year ago with the College of Surgeons of England, by which body it was purchased, and in whose museum it has now been arranged in such a manner as to be accessible to all workers at anthropology. Such a collection as this, well cared for in a public museum, is a solid and permanent increase to the wealth of the country, for even if the methods of investigation now used are superseded by others, and the present literature comes to be looked upon as obsolete, the specimens will remain as materials for building up the history of the human race; and as the interest in the subject increase - -as it certainly will--many of these evidences of the physical structure of people passed or passing away will come to be objects of priceless value.

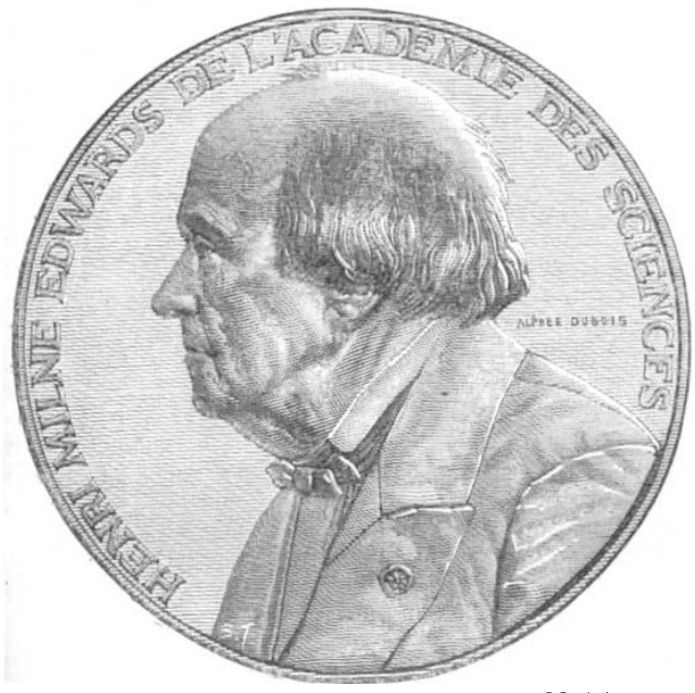

\title{
M. H. MILNE-EDWARDS
}

WE referred some time ago to the fact that a medal, subscribed for by a number of his admirers, had been presented to the venerable zoologist, M. H. MilneEdwards. No one better deserves such a recognition.

Medal presented to M. H. Milne-Edwards.

and none know better than the French how to do such an honour gracefully and impressively. Our illustration is reproduced from La Nature of May 7, where will be found a pretty complete list -and it is a long one-of $M$. Milne-Edwards' works. The medal, a production of some artistic merit, is the work of M. Alphée Dubois.

\section{THE ZOOLOGICAL RESULTS OF THE SOCOTRAN EXPEDITION}

$\mathrm{A}^{\mathrm{T}}$

the meeting of the British Association in 1878 , upon the motion of Mr. Sclater, a Committee, consisting of Dr. Hartlaub, Sir Joseph Hooker, Capt. J. W. Hunter, Prof. Flower, and the mover, was appointed to take steps for the investigation of the natural history of Socotra. Socotra, it was stated, was one of the few spots in the world which seemed never to have been trodden by the foot of the naturalist, and would in all probability be found to contain distinct insular forms, of which it would be highly interesting to know the relations, and to secure specimens for our collections.

The grant of Iool., given by the Association for this excellent object, having been subsequently increased by two sums devoted to the same purpose out of the Government Fund of $4000 \%$. administered by the Royal Society, the Committee felt strong enough to proceed to action, and in the winter of 1879 were fortunate enough to secure the services of Prof. J. B. Balfour, of the University of Glasgow, for a special expedition to the island.

Prof. Balfour left England on January 9, I880, accompanied by Alexander Scott, a gardener from the Royal Botanic Gardens, Edinburgh, as collector, and reached Aden by the French mail on the 24 th, where he obtained every sort of advice and assistance from the civil and naval authorities for his expedition. Owing to adverse winds and other difficulties Prof. Balfour did not manage finally to reach Socotra until February in, when the party, which had been reinforced by the addition of Lieut.
Cockburn of the 6th Royals and a corps of attendants from Aden, were put on shore at Gollonsir, a village situated at the north-west end of the island, by H.M.S. Seagull. In his report to the. Socotran Committee Prof. Balfour gives the subjoined account of his subsequent proceedings :-

"Making in the first instance Gollonsir our headquarters, we explored the adjacent country to the south and south-west until February 25, when we struck tents, and sending our heavy baggage and stores by sea, started to march to Hadibu. We took four days to accomplish this, reaching Hadibu late on the night of the 28 th inst.

"Having communicated to the Sultan the fact of our arrival, he came to Hadibu on March 1 , when we had an interview.

"Establishing our depôt now on the Hadibu plain, about a mile from the town, we spent the time until the 7 th inst. investigating the magnificent Haggier range of hills shutting in on the south the Hadibu plain.

"On March 8, leaving a tent-Lascar in charge of the depôt at Hadibu, we started upon a trip to the eastern end of the island, going eastward along the northern side and returning westward by the southern side of the island. During this trip we reached Ras Momé, the extreme eastern headland. Camp at Hadibu was again entered on March 18.

"As yet we had not seen much of the southern parts of the island, so on March 22 we left Hadibu on our last excursion. Crossing the Haggier range we emerged upon the southern shore at Nogad, traversed the coast-line for some distance, and then recrossed the island so as to 